Van Dam, S., \& Van Reijmersdal, E. A. (2019). Insights in adolescents' advertising literacy, perceptions and responses regarding sponsored influencer videos and disclosures. Cyberpsychology: Journal of Psychosocial Research on Cyberspace, 13(2), article 2. http://dx.doi.org/10.5817/CP2019-2-2

\title{
Insights in Adolescents' Advertising Literacy, Perceptions and Responses Regarding Sponsored Influencer Videos and Disclosures
}

\author{
Sophia van Dam¹ \& Eva A. van Reijmersdal ${ }^{1}$ \\ ${ }^{1}$ Amsterdam School of Communication Research ASCoR, University of Amsterdam, The Netherlands
}

\begin{abstract}
Increasingly, online video creators are promoting brands to their network of adolescent followers, a phenomenon known as video influencer marketing. Both the vulnerability of adolescents and the lack of sponsorship disclosures raise concerns about the ethics of influencer marketing. Through focus groups (20 participants, aged 12 to 16), we investigated adolescents' awareness and understanding of the presence of persuasive content in influencer videos (i.e. conceptual advertising literacy), their moral and evaluative perceptions of this content (i.e. attitudinal and moral advertising literacy), their perceptions of disclosures, and the role of disclosures in their evaluations of the sponsoring brand and the influencer. Results show that adolescents are accepting of sponsorships and show compassion toward the influencers instead of having a critical perspective. Moreover, disclosures are appreciated as long as they do not disturb the editorial-commercial balance of the sponsored video. However, when a disclosure does disturb this balance, adolescents report reactance and negative brand evaluations. The results contribute to the theoretical understanding of adolescents' advertising literacy of video influencer marketing and provide practical guidelines for establishing disclosure policies.
\end{abstract}

Keywords: Adolescents; influencer marketing; disclosures; sponsored content; persuasion knowledge; advertising literacy

\section{Introduction}

Adolescents are frequent viewers of online videos that are created by online influencers and distributed via social media platforms such as YouTube (DefyMedia, 2016). Online influencers are 'people who have built a sizeable social network of people following them' (De Veirman, Cauberghe, \& Hudders, 2017, p. 798). Influencers are often perceived as credible trendsetters in one or more niches. (De Jans, Cauberghe, \& Hudders, 2018; De Veirman, Cauberghe, \& Hudders, 2017). The increasing popularity of online influencers, especially among minors, has awakened interest of brands. Minors are hard to reach via more traditional media such as television and print and therefore, advertisers have started collaborations with online influencers (Arnold, 2017), a phenomenon known as video influencer marketing.

Video influencer marketing can be seen as a form of native advertising, as it masks the persuasive nature of the content, by embedding the sponsored message into entertaining or informative content created by a third party (i.e., the influencer; Evans, Phua, Lim, \& Jun, 2017; De Veirman et al., 2017). Due to the subtle nature of these sponsorships, adolescents are unlikely to be aware of the commercial content (Hudders et al., 2017; Moore \& Rideout, 2007). Advertising literacy refers to consumers' beliefs about the tactics, intentions, and strategies that are used in persuasive attempts, in the context of advertising (Friestad \& Wright, 1994; Hudders et al., 2017). 
The hidden character of online sponsored content is not the only factor that complicates awareness of its persuasive nature. The characteristics of the adolescent target group also play an important part. This group's cognitive skills, which are necessary for advertising processing, have not yet matured. In particular, adolescents' advertising literacy has not yet reached an adult level, which may make it harder for them to understand the persuasive nature of online sponsored content (Van Reijmersdal, Boerman, Buijzen, \& Rozendaal, 2017). Also, the affective parts of their brains are hyper-responsive, making adolescents susceptible to arousing stimuli such as sponsored influencer videos (Defoe, Dubas, Figner \& Van Aken, 2015).

Clear evidence is still lacking concerning adolescents' advertising literacy within the context of influencer marketing videos. There are studies on adolescents' advertising literacy regarding other types of online sponsored content, including advergames (Verhellen, Oates, De Pelsmacker, \& Dens, 2014), personalized and targeted advertising on social networking sites (Zarouali, Poels, Ponnet, \& Walrave, 2018; Zarouali, Ponnet, Walrave, \& Poels, 2017), and social network games (Rozendaal, Slot, Van Reijmersdal, \& Buijzen, 2013; Vanwesenbeeck, Ponnet, \& Walrave, 2017; Vanwesenbeeck, Walrave, \& Ponnet, 2016). However, these studies cannot be translated directly to influencer marketing. Influencer marketing is unique in the sense that adolescents often build strong (parasocial) relationships with influencers and even perceive them as their friends (Hwang \& Zhang, 2018). Because people with whom you have strong relationships are usually not expected to have ulterior motives, it may be even harder than for other online sponsored content to think about the persuasive nature of influencer marketing (Campbell \& Kirmani, 2000; Van Noort, Antheunis, \& Van Reijmersdal, 2012).

Before further steps can be taken to empower adolescents and help them better understand the persuasive nature of sponsored influencer videos, it is essential to explore adolescents' advertising literacy concerning these videos. Therefore, the first aim of this study is to investigate the nature and extent of adolescents' (aged 12 to 16) advertising literacy regarding sponsored influencer videos.

A way to empower young consumers to be able to evaluate advertising critically is to use disclosures. Disclosing the persuasive nature of a message is a tool to inform adolescents (Moore \& Rideout 2007; Rozendaal, Lapierre, Van Reijmersdal, \& Buijzen, 2011). International authorities (such as the Committee of Advertising Practice, the Federal Trade Commission) have already proposed guidelines for disclosing online sponsored content, mostly stressing full disclosure of advertising by making the relationship between the brand and the influencer clear (CAP, 2018; ICAS, 2018). Studies on the use of sponsorship disclosures showed that disclosures in movies were evaluated negatively by adults (Van Reijmersdal, Tutaj, \& Boerman, 2013) and that disclosures in television brand placement did not alter adolescents' attitude toward the brand (Van Reijmersdal et al., 2017).

The second aim of this study is to explore adolescents' perceptions of sponsorship disclosures for sponsored influencer videos and the role disclosures play in their evaluations of the brand and the influencer. We think it is important to provide further insights into adolescents' perceptions of disclosures, because adolescents are more and more likely to encounter disclosures while using influencer content. In the present study, we focus on textual disclosures that could be shown before or during the video. This type of disclosure is one of the suggested formats to inform the audience which has been found to be effective among adults (CAP, 2018; ICAS, 2018; Federal Trade Commission, 2009).

Insights from this study may contribute to our theoretical understanding of adolescents' advertising literacy regarding a particular popular form of marketing, that is influencer marketing. Furthermore, it will provide insights in adolescents' perceptions of the use of disclosures in influencer marketing and the role that disclosures play in their evaluation of the brand and the influencer itself. The outcomes of this study can be of practical guidance for disclosure policy.

\section{Activation of Advertising Literacy}

The Persuasion Knowledge Model (PKM) by Friestad and Wright (1994) explains how people cope with persuasive messages. When people are exposed to a persuasive message, they tend to activate knowledge about tactics used in persuasive attempts. Advertising literacy, one's persuasion knowledge in the context of advertising, helps individuals identify and cope with the persuasive attempt. When adolescents watch sponsored influencer videos 
and are aware that these contain sponsored messages, their advertising literacy might be triggered. Hudders et al. (2017) differentiate between three dimensions of advertising literacy.

The first dimension comprises conceptual advertising literacy, which refers to the ability to recognize a commercial message and its intentions. Specifically, this dimension entails the ability to differentiate the persuasive message from other content (recognition of advertising), understanding its intention to sell products (selling intent), its intention to influence behaviour and attitudes (persuasive intent), recognition of the messages' source, and the understanding of persuasive tactics in general (Hudders et al., 2017; Rozendaal et al., 2011).

The second dimension is moral advertising literacy and refers to moral perceptions of appropriateness and acceptance of persuasion, or in our case, influencer marketing (Hudders et al., 2017). For example, people may perceive influencer marketing as an unacceptable practice. They may think it is morally wrong because of its lack of transparency. Or people may perceive influencer marketing as acceptable, because influencers need income to create their content. People's moral advertising literacy is in part determined by the norms in society about advertising and persuasion (Hudders et al., 2017).

The third dimension is attitudinal advertising literacy which is evaluative in nature. This dimension involves disliking of advertising and scepticism, which are attitudes that counterbalance the positive affective responses evoked automatically by the entertaining character of most new online advertising formats (Rozendaal et al., 2011). This critical attitude enables one to decide to either accept or reject the persuasive attempt (Rozendaal et al., 2011).

Furthermore, advertising literacy can be dispositional or situational. Dispositional advertising literacy comprises knowledge, beliefs and abilities someone has regarding advertising (Ham, Nelson \& Das, 2015; Hudders et al., 2017). Situational advertising literacy is situation specific and refers to the actual activation of the dispositional knowledge when exposed to a persuasive attempt. While adolescents might have a general conceptual, moral and attitudinal knowledge of influencer sponsorships (i.e. dispositional knowledge), situational activation of this knowledge might be complicated due to its hidden and integrated character (Hudders et al., 2017; Livingstone \& Helsper, 2006; Verhellen et al., 2014), especially compared to traditional formats (such as TV commercials). Additionally, adolescents' dispositional advertising literacy has not yet fully developed due to specific characteristics that are indicative of adolescence, which may further hamper the activation of their situational advertising literacy.

To start, the adolescent brain is still developing. The pre-frontal cortex, the part of the brain that is important for planning, consequence awareness, and decision making and judgement develops throughout adolescence up to the point of emerging adulthood (Defoe et al., 2015). These cognitive processing skills are necessary to effectively activate and apply advertising literacy as a critical defence when confronted with advertising messages (Rozendaal et al., 2011). Moreover, the affective parts are hyperactive during early adolescence which leads to increased susceptibility to affective stimuli, such as influencer videos. Also, adolescents are more sensible to their environment as they are in the midst of the development of a stable identity. Adolescents need to experiment with their behaviour in order to find out what others appreciate or dislike about them. Close friends and peers play a crucial role in practicing social skills and sharing experiences (Valkenburg \& Piotrowski, 2017). Nowadays, this happens on social media, as these offer the opportunity to communicate endlessly with peers in order to validate one's own identity (Valkenburg \& Piotrowski, 2017). As online influencers nowadays confiscate a large part of social media (DefyMedia, 2016), they also serve as role models to learn 'appropriate' behavioural options. Moreover, adolescents perceive online influencers often as their friends and build parasocial relationships with them (Hwang \& Zhang, 2018). Thus, influencers are perceived as friends and therefore less expected to have ulterior motives (Campbell \& Kirmani, 2000). Advertising literacy is less easily triggered which may increase the impact of sponsorships within influencer content on adolescents (Van Noort et al., 2012).

However, empirical evidence is still missing about the current state of adolescents' conceptual, moral, and attitudinal advertising literacy within the context of influencer marketing. Most studies on advertising literacy have focused on children's ability to discern between advertising on traditional media platforms (such as commercial breaks and television programmes: Van Reijmersdal, Lammers, Rozendaal \& Buijzen, 2015; Vanwesenbeeck et al., 2017; Verhellen et al., 2014) or their capacity to understand the advertiser's commercial intent in the case of for 
instance, brand placement (Van Reijmersdal et al., 2017). One qualitative study explored the understanding and moral judgements of various novel advertising tactics among children (9- to 11-year-olds; De Pauw, De Wolf, Hudders, \& Cauberghe, 2018). De Pauw et al. (2018) found that while children do not instinctively evaluate new advertising formats critically, they can be empowered by providing them with both awareness and understanding of hidden tactics.

There is a growing base of research on adolescents' advertising literacy within an online context, focusing on advergames (Hudders et al., 2017; Van Reijmersdal et al., 2015; Verhellen et al., 2014), social network games (Vanwesenbeeck et al., 2016; Vanwesenbeeck et al., 2017), targeted advertising on social networking sites (Lawlor, Dunne, \& Rowley, 2016; Zarouali, Poels, Walrave, \& Ponnet, 2018; Zarouali et al., 2017).

For example, Zarouali, Poels, Walrave et al. (2018) showed that advertising on Facebook that makes uses of your social ties generates more positive attitudes and less advertising literacy among adolescents (14- to 16-year-olds). When these adolescents are engaged in peer communication on Facebook and when it's a strong social tie, the effect is even stronger (Zarouali, Poels, Walrave et al., 2018). Translating this to the current context, adolescents might be susceptible to advertising via online influencer content as they are engaged in the platform through watching (and maybe commenting or liking) the video, and the influencer is likely to be perceived as a peer. The lack of situational advertising literacy of adolescents was shown through a study conducted by Lawlor et al. (2016). They investigated adolescent girls' (12- to 14-year-olds) knowledge of integrated and interactive advertising on social network sites. Even though the girls purported to be fully aware of the integrated advertising, it turned out that they did not recognize the hidden commercial messages (such as sponsored posts) when they were exposed to them (Lawlor et al., 2016). Next to their inability to recognize the sponsored posts, they were unaware of the persuasive intentions of these practices. This shows the discrepancy between their self-reported and actual advertising literacy.

Clearly, only limited information about adolescents' understanding and knowledgeability of online influencer marketing exists. Therefore, the following research questions are developed:

RQ1a: What is adolescents' conceptual advertising literacy with respect to sponsored influencer videos, specifically (1) recognition of advertising; (2) understanding selling intent; (3) understanding persuasive intent; (4) recognition of advertising's source; and (5) understanding of persuasive tactics.

RQ1b: What is adolescents' moral advertising literacy with respect to sponsored influencer videos?

RQ1c: What is adolescents' attitudinal advertising literacy with respect to sponsored influencer videos, specifically (1) disliking; and (2) scepticism?

\section{Perceptions of Disclosures of Influencer Content}

Disclosing sponsored influencer content is often proposed as a solution for the lack of transparency and ethics of the influencer practice. International authorities such as the Committee of Advertising and the Federal Trade Commission stress to fully disclose sponsored content by clearly indicating the relationship between the brand and the influencer (CAP, 2018; Federal Trade Commission, 2009). The objective is to make youth aware of the content's commercial nature so they can make informed decisions about their interaction with the advertising and the weight they would give the information conveyed in the advertisement (CAP, 2018). While the concerns of parents, educational professionals, and policy makers are acknowledged in the current debate, it seems that the most important group, the adolescents, has been overlooked.

Van Reijmersdal et al. (2013) studied adults' perceptions of textual sponsorship disclosures shown in movies. They demonstrated that adults evaluated the disclosures negatively: they found them irritating and not useful. During the study of De Jans, Vanwesenbeeck et al. (2018) co-creation workshops showed that children (6- to 11-years-old) preferred a disclosure that states 'Advertising!' including contrasting colours and shapes. The child-inspired disclosure also led to a better recognition and understanding compared to current used disclosures. There is no available information at this point of adolescents' perceptions of the use of textual disclosures before or during sponsored influencer videos, and to what extent they feel the need for these online sponsorship disclosures. 
Therefore, it would be interesting to obtain insights into the viewpoint of today's adolescents on disclosures. Hence, the second research question was proposed:

RQ2: What are the perceptions of disclosures for sponsored influencer videos among adolescents?

\section{The Role of Textual Disclosures in Evaluations of the Brand and the Influencer}

Insights into the role of disclosures in adolescents' evaluations of the sponsoring brand and of the influencer itself are limited. Research among adults has shown that disclosures can trigger advertising literacy (Campbell, Mohr, \& Verlegh, 2013). Activated advertising literacy can increase the motivation to resist the message by promoting feelings of psychological reactance (Brehm, 1966). In other words, cases in which someone is actually aware that the source is telling them what to think and feel are perceived as restrictions of freedom and therefore, motivate people to actively restore this freedom. Reactance produces resistance to persuasion through, for instance, critical evaluation of the message.

Next to psychological reactance, the change in meaning principle (Friestad \& Wright, 1994) can occur when adolescents discover the actual intent of the content because of a disclosure. This causes a redefinition of the content's meaning from merely entertaining or informative to persuasive. When adolescents realize that the content they were watching was not meant to entertain them, but actually to sell them certain products, they can feel fooled; this realization will motivate them to process the content more critically. And, this can change the way adolescents view the influencer.

Experimental studies among adults showed mixed effects of disclosures via advertising literacy on brand responses in several media (Campbell et al., 2013; Van Reijmersdal et al., 2015; Wojdynski \& Evans, 2016). Only a handful of studies on disclosures have been conducted among children (6- to-11-years old: De Jans, Vanwesenbeeck et al., 2018; 11- to 14-years old; De Jans, Cauberghe et al., 2018; 9- to-11-years-old: De Pauw et al., 2018; 7- to-11-years-old: An, Jin, \& Park, 2014). These showed that while children have a basic dispositional conceptual advertising literacy, they do not activate this knowledge when exposed to new embedded advertising formats. However, when children are informed about hidden advertising techniques before exposure to sponsored content, by explaining face-to-face how these practices work (De Pauw et al., 2018) via an educational game or through an intervention (An et al., 2014; De Jans, Cauberghe et al., 2018), they seem able to activate their situational knowledge of persuasion (De Pauw et al., 2018).

Meanwhile, adolescents and their responses to disclosures and advertising have been mostly neglected in literature. There has been one study that tested adolescents' responses to disclosures of television brand placement (Van Reijmersdal et al., 2017). This experiment found effects of disclosures on adolescents' understanding of the persuasive intent of the placement and on brand memory but not on brand attitude. Until now, empirical research is lacking as to whether these responses occur in the context of sponsored influencer videos as well. The question arises what the role of disclosures is in adolescents' evaluations of the brand and the influencer and in the activation of processes such as reactance and change of meaning. Therefore, the following research question is formulated:

RQ3: What is the role of disclosures for sponsored influencer videos in adolescents' evaluations of the brand and the influencer.

\section{Method}

\section{Participants and Procedure}

In order to answer the research questions, qualitative focus group discussions were held with 20 adolescents between 12 and 16 years old (40\% female), all following the two highest levels of high school education. Focus group discussions reflect the free-flowing, social ambience of online media, offering the participants an opportunity to discuss their use of these platforms and their awareness of commercial messages within online content. Participants were recruited via a secondary school in a medium-sized city in The Netherlands. In order to ensure variation in this sample, purposeful sampling was used based on high school grade. A total of four focus 
groups with five adolescents each were held. The composition of the focus groups was determined by the teacher. The teacher was instructed to make a diverse selection in such a way that not only the most talkative or overachieving students were chosen, but also more timid students. The discussions were audio recorded. Focus group 1 consisted of male and female students from the first grade, ages 12 and 13 years old. Focus group 2 consisted of male and female students from the third grade, ages 14 to 16 years old. Focus group 3 and 4 consisted of male and female students from the second grade, ages 13 to 15 years old.

The focus group discussions were conducted within the school setting in a separate room. The first author of this article conducted the focus group and thus was present during all of the discussions. The first author, a young woman who was a Research Master's student then, was open to hear the adolescents' answers and was very interested in the topic. She built good rapport with the adolescents. Before the study started, IRB approval was granted by the university, and informed consent was obtained from the schools, parents, and participants.

The focus groups were semi-structured, and an interview guide was used (see Appendix), to ensure consistency in topics and questions across groups, yet also allowing for some flexibility within the topics. The three main topics in the discussion reflected the three research questions of the study. To cover these topics in an interactive and informal way, each focus group discussion was divided into four parts. First, the participants were welcomed. It was emphasised that these focus groups were not tests; thus, there were no right or wrong answers. Also, the participants were encouraged to give everyone a chance to speak without interrupting each other.

The second part consisted of questions about the participants' familiarity with YouTube and influencer videos. The researcher probed for the type of videos in which the participants were interested and the manner in which they encountered brands in these videos. After this discussion, the third part started with an influencer video sponsored by the brand Doritos. The video was used in order to start a discussion and to ensure that all participants were talking about the same kind of content. The influencers in the video tried a new flavour of Doritos through a game. This video was chosen as it was an existing video made by known influencers to stay true to the topic. Moreover, this video was undoubtedly created as a result of a paid collaboration between Doritos and the influencer. Also, it was important that the video was neither too obvious in its selling intent nor too subtle, to capture the hidden character of online sponsored influencer videos. The brand and the product were clearly visible throughout the video, without the selling intent being too obvious.

The participants were asked to individually write down their thoughts on sticky notes while watching the video. In this way, independent thinking was encouraged before the group discussion started. The sticky notes were discussed and categorised, leading to a big mind map in the middle of the table. The researcher focused primarily on anything written down that had to do with a brand, sponsorship, or advertising. Consequently, questions about participants' opinions and moral judgment about the sponsored content were asked. In this way, not only the conceptual dimension of advertising literacy could be examined, but also the participants' moral and attitudinal advertising literacy.

The fourth and last part of the focus group discussion entailed the participants' perceptions of disclosing sponsorships within influencer videos and the role of these disclosures in their evaluations of the brand and the influencer. The researcher briefly explained that several institutions suggested the use of a disclosure to inform audiences about influencer sponsorships, but that it was not clear how this should be implemented. Participants were asked to individually write down what they thought proper implementation of a sponsorship disclosure for sponsored influencer videos should look like. Afterwards, these ideas were shared and discussed within the group. The researcher probed the participants' perceptions and motivations behind their opinions and whether disclosures play a role in their evaluation of the sponsoring brand and the influencer itself. After this short discussion, two written disclosures were shown, and the participants were asked to give their opinions about these disclosures. The disclosures were shown separately from the video but were related to the video and influencer. The first disclosure was '(YouTube influencers) are paid by Doritos to advertise in this video', and the second was '(YouTube influencers) are paid by Doritos to advertise in this video so you will like Doritos'; thus, the second disclosure also disclosed the persuasive intent. These disclosures were based on previous studies on disclosures for embedded advertising and considering the purpose of a disclosure, which is firstly to help adolescents to recognize the commercial message and secondly to disclose its persuasive intent (c.f., Dekker \& Van Reijmersdal, 
2013). Above all, this type of disclosure is one of the suggested formats to inform the audience (CAP, 2018; ICAS, 2018; Federal Trade Commission, 2009).

To conclude the focus groups, the participants were thanked and given the possibility to ask questions. The focus group discussions lasted for approximately 50 minutes, which was equal to the duration of the participants' classes.

\section{Analysis}

After verbatim transcription, the data were analysed by the same researcher who did the focus groups, using the computer program Atlas.ti. The focus group discussions were read line by line, and codes were assigned to words and sentences. This coding was focused (Charmaz, 2006), whereby the concepts within the three main topics provided an angle for looking at the material. This indicates that the concepts within conceptual, moral and attitudinal advertising literacy were considered while coding the statements of the adolescents within the first part of the focus groups. Next to advertising literacy, codes were assigned to adolescents' perceptions of sponsorships in influencer videos, the use of disclosures and adolescents' responses to disclosures. While the coding of the data was guided by the topics and interpretations of the researchers (etic approach), it remained of highest importance that the perspectives, beliefs, and meaning given by the participants were dominant during coding (emic approach).

All discussions were coded separately, resulting in a long list of codes mostly relating to one of the three main topics (advertising literacy, perceptions of disclosures, the role of disclosures in evaluations of the brand and the influencer). Preliminary findings, thoughts, remarkable statements, or behaviours noticed during the coding were written down as a memo (such as use of the term 'sponsorship').

The second step in the process consisted of structuring the codes (such as 'realization', 'intentions', 'subconscious', 'recognition of brands') by categorising them and specifying relationships between them. Related codes were grouped together within the same theme to gain insights into the various elements playing a role within each topic. An overview was created consisting of theme-categorized codes, memos and quotes. Finally, findings within this overview were classified within the three topics of the focus group discussions.

We applied various techniques to safeguard the credibility of the results and to optimize the transparency of the research process. Research triangulation (Flick, 2014) took place in such a way that the analysing author discussed the codes and preliminary findings with the other author making sure that the authors agreed on the codes and categorizations. Theory triangulation took place by using the original PKM (Friestad \& Wright, 1994), but also extended and updated advertising literacy theories (Evans \& Park, 2015; Hudders et al., 2017; Rozendaal, et al., 2011). By doing so, we verified the validity of our interpretations.

Another part of our research process is, prolonged engagement, meaning that the researchers have considerable contact with the field of study (Flick, 2014). The first author gained expertise in conducting research on sponsored content among minors during her internship. During her studies, she developed a strong interest in working with minors and understanding their perceptions of online sponsored content. The second author is an academic researcher specialized in minors' advertising literacy of online content and sponsorship disclosures. This engagement of the researchers enabled us to enhance the interpretations of the focus group materials and, as such, optimize the credibility and ecological validity (Braun \& Clarke 2013) of our results. One could contend that our engagement with the field may lead to bias, however, the researchers did not have an interest in specific answers and were open to all kinds of perceptions of the adolescents.

To assure internal validity, two measures were taken. First, the memos written during the study served as interpretation of the data during analysis and detection of any biases. The second measure consisted of member checks (Flick, 2014), which entailed that the researcher often summarised or repeated the participants' answers so the participants could correct the researcher if the researcher had misinterpreted the participants' answers. 


\section{Results}

\section{Conceptual Advertising Literacy}

With respect to RQ1, the following elements of conceptual advertising literacy (Rozendaal, Opree, \& Buijzen, 2016) were expressed by the adolescents: (1) recognition of advertising; (2) understanding selling intent; (3) understanding persuasive intent; (4) recognition of advertising's source; and (5) understanding of persuasive tactics in general.

Regarding recognition of persuasive messages, participants reported to be aware of the integrated sponsored content in general: '... they try to do it [advertise on YouTube] unnoticeable in between [the editorial content]' (FG1, 12to 13-year-olds), 'If they advertise during the video, you will notice' (FG4, 13-to 15-year-olds). When asking whether participants had ever noticed brands on YouTube, they acknowledged this observation and provided examples from their own experiences: 'Sometimes you notice that they randomly drink Pepsi' (FG1, 12- to 13-year-olds). This reported ability to recognize commercial messages in YouTube videos was also confirmed after the participants were exposed to the sponsored video as the sponsored brand emerged in the conversations: 'This whole video, which was like 10 minutes, is actually secretly only about Doritos' (FG2, 14- to 16-year-olds). Remarkably, participants showed confidence in their abilities to recognize sponsored content while indicating that it could be difficult for others to recognize the hidden advertising. 'Some people will know this [the hidden advertising], and some people won't notice, but I do notice it immediately' (FG3, 13- to 15-year-olds). However, later on in the discussions doubts about whether content is sponsored were expressed as well. Thus, participants may overestimate their own ability to recognize sponsored content as such.

The selling intention of advertising was mentioned in the discussions and was even pointed out as the main goal of sponsored content: 'They do this with the Doritos challenge so the people who watch this want to buy Doritos to do the challenge too' (FG3, 13- to 15-year-olds). However, understanding of persuasive intentions of the sponsored content such as the intention to enhance brand attitude or brand awareness were not expressed.

With respect to the persuasive tactics used within influencer marketing and accentuating its integrated and hidden character, the participants seemed knowledgeable: 'Of course they will not say that [that it's advertising] the whole time. It is not that you've been watching a true advertisement for ten minutes, but it is the whole time focused on a product which they actually want to sell to you. (FG2, 14- to 16-year-olds)' They even made comparisons between advertising in YouTube videos and television advertising, underlining the integrated and hidden character of the first: "I think that [advertising] within YouTube is that they [the advertisers] try do it [the advertising] unobtrusively [in the video]. With [television] advertising you just know the purpose' (FG1, 12- to 13-year-olds). Moreover, familiarity with concepts within the current advertising practice was expressed by the use of words such as 'sponsoring' and 'sponsorships' throughout the focus group discussions.

Regarding recognition of the source of the persuasive message, the participants did not really present their thoughts on this topic. it was mentioned that the video was made as a result of a collaboration between an influencer and a brand: 'When they are reviewing beauty products, they always mention the brands they use. (FG3, 13to 15-year-olds)'. In addition to the brand itself, YouTube as the source of advertising was mistakenly mentioned as well. One participant suggested that YouTube collaborated with a brand to sponsor an influencer. 'For example, Center Parks. If they sponsor, YouTube will give them money, so the YouTuber visits them and makes a video. Many people will watch this video and thereafter want to visit Center Parks' (FG1, 12- to 13-year-olds).

Finally, a new element of conceptual advertising literacy emerged from the data. This involved the participants' awareness of the sponsorship mechanism as a revenue model behind influencer marketing. They were aware of the fact that the influencer receives money from a brand to advertise in their videos and that this advertising is mostly integrated within the editorial content. 'Companies invest in [integrated advertising via] YouTube to make more people interested in the products they sell' (FG1, 12- to 13-year-olds), 'They [the influencers] make the video to get money. They get money from the sponsor, Doritos' (FG3, 13- to 15-year-olds). 


\section{Moral Advertising Literacy}

With respect to moral advertising literacy, the adolescents report little concerns. Rather they express acceptance of influencer marketing as being a logical and necessary part of the business model of influencers. Their lack of moral judgment can be divided into three aspects. First, adolescents' understanding of the revenue model of influencer marketing bolstered their positive moral judgment of sponsored influencer videos. The adolescents in this study argued that online influencers have to engage in advertising; otherwise, they would not be able to spend so much time on making videos. 'I don't really care [about the sponsorships], I mean, they also have to make money and this is how they do it' (FG2, 14- to 16-year-olds).

Second, the sponsorship was perceived not only to benefit the influencer but also the audience as the participants argued that the money earned by influencers will be used to make better videos. 'I actually do like it [the sponsorships], because most of the times when they [the influencers] are sponsored this means they have more money so they can do more fun stuff, or they make better videos. Thanks to the sponsors' (FG1, 12- to 13-year-olds). These perceptions seem to attribute to positive moral advertising literacy.

Third, the participants' relationships with influencers appeared to be important. 'I think that if you're watching YouTube [videos], you're feeling a certain connection [with the influencer]' (FG4, 13- to 15-year-olds). This thinking resulted in a certain compassion: 'Sometimes I think, I want it [receiving products from brands] too, but then I think, she [the online influencer] works really hard, so she deserves it. (FG4, 13- to 15-year-olds)'

\section{Attitudinal Advertising Literacy}

The current study showed a lack of scepticism and liking of influencer marketing. The adolescents in this study only showed annoyance with sponsorships when sponsorship was perceived as excessive compared to the editorial content within a video (see results RQ2), for example when a brand is mentioned constantly: 'In my opinion it [advertising] is not that bad, but in certain vlogs or videos the advertising is really disturbing as they overdo it a lot' (FG4, 13- to 15-year-olds).

The participants reported that they perceived the medium to be genuine and the influencers to be honest. Adolescents seemed to value these characteristics and showed that those characteristics are mainly the reasons to watch YouTube videos instead of television: "I have the idea that YouTube is honest, or at least more honest than television. And this makes you more attracted to it' (FG4, 13- to 15-year-olds). This perceived honesty appeared to be the most important reason for the adolescents to hold a low level of scepticism towards the influencers' content.

However, doubts about the truthfulness of influencer videos were also expressed. It seemed that experience with videos, which they thought to be only for entertainment but turned out to be commercial, aroused their scepticism: 'Now it's like it's only about Doritos and not for fun (...) Like it's only about Doritos, it's not about entertainment anymore, but only about Doritos wanting money so you have to buy it [the product] (FG4, 13- to 15-year-olds). This indicates the change of meaning principle, whereby the realization of the real intention of the sender causes a change in perception of the message. These adolescents also showed that they appreciated videos that are true and consist of honest information about a product: 'I don't care whether it is sponsored or not, but sometimes it is annoying if you're doubting whether it is sponsored or not. Then it would be nice to know whether this is the case' (FG3, 13- to 15-year-olds).

Furthermore, their confidence in recognizing advertising contributed to the casual attitude towards sponsored content. 'Most of the times you just notice whether a person [an influencer] is sincere or not, because when I notice that someone is not honest, I like it a lot less' (FG3, 13- to 15-year-olds).

\section{Perceptions of Disclosures in Influencer Content}

With respect to RQ2, the perception of disclosing the sponsored content among adolescents was explored. Adolescents in this study did not appreciate disclosures that too clearly conveyed that the video was presenting advertisements. They preferred a disclosure by the influencers themselves in which less explicit wording is used (such as collaboration with a brand instead of advertising for a brand), or either a written disclosure hidden in the 
description underneath the video, a disclosure that is integrated within the video (such as a logo in the video that does not distract) or preferably, no disclosure at all. In their eyes, a clear disclosure emphasized the commercial message too much and disrupted the perceived balance between entertaining and persuasive content: "In my opinion it should not be too pushy, like, this is advertising, because then you will keep this in mind all the time. Just indicating is fine, but it should not be visible all the time' (FG3, 13- to 15-year-olds). Influencer marketing was no longer acceptable if a disclosure puts too much emphasis on the commercial content: 'But if you say this [a written disclosure of the sponsorship] in the beginning, then the whole video will be less amusing, as you will notice all things sponsored' (FG3, 13- to 15-year-olds).

Adolescents seem to prefer to be left in the dark with regard to the content's sponsorship rather than to be informed about it. This contradicts their reported awareness of the sponsorships because if they really were aware of the sponsorship, a disclosure would not have added new information and would not have affected the viewing experience.

\section{The Role of Disclosures in Evaluations of Influencers and Brands}

As previously mentioned, a clear disclosure was perceived by our sample as a disturbance of the balance between the editorial and commercial content. As a result of this imbalance, several forms of resistance were expressed including reactance, avoidance, and irritation.

Reactance became apparent when it was reported that the disclosure made the participants feel their freedom was being restricted: 'Like I said, I don't really like it [a written disclosure of sponsorship and persuasive intent] as I think you should decide yourself what to like' (FG3, 13- to 15-year-olds). Adolescents responded negatively: 'It [the disclosure] sounds weird, like [the video is only made so] you have to buy the brand.' (FG4, 13- to 15-year-olds), 'I think I wouldn't like it [the video] anymore, only because they are saying 'you have to buy this' (FG4, 13- to 15-year-olds). It was also reported that videos were avoided when one was aware of the sponsored content in it. Other respondents elaborate on their irritation after they are exposed to a disclosure, which makes them like the content less and therefore they do not like the use of a disclosure in influencer videos: "I would think like... I don't know, I would still finish watching it [the sponsored video], but I think I would like it less, just because they say [the disclosure] you have to buy this' (FG4, 13- to 15-year-olds).

The change of meaning principle was apparent, as the participants indicated that a clear written disclosure altered their perception of the video and the intentions of the influencer: 'First I thought it would be nice to do it [the Doritos challenge]. But now that I see the disclosure it's like the whole video is only about Doritos and it's not for the fun but like Doritos wants money, so you have to buy it'(FG4, 13- to 15-year-olds). They expressed more negative attitudes towards the brand and less desire to have the product when they became aware of the ulterior intention of the video.

Also, disclosures played a role in the participants' evaluations of the influencer itself. As a participant indicated after seeing a written disclosure of the selling intent and the source of the sponsorship: 'If you put it [the disclosure] at the top [of the video] it is like: we only make these videos because we are getting paid by those brands. That's kind of an asshole thing to do' (FG4, 13- to 15-year-olds).

The negative responses to the disclosures are further illustrated by perceptions of dishonesty: "It seems very negative. In the way that they only make the vlog, not because they like it, but because they get paid for it' (FG2, 14- to 16-year-olds).

\section{Discussion}

The aim of this study was to provide insights into adolescents' understanding of influencer marketing, their conceptual, moral and attitudinal advertising literacy, and an exploration of their perceptions of sponsorship disclosures. In addition, insights into the role of disclosures in adolescents' evaluations of the sponsoring brands and influencers were gathered. Three conclusions can be drawn.

First, adolescents' advertising literacy regarding influencer marketing seems dissociated in various ways. The adolescents in our study claimed to be fully aware of influencer marketing, that is, they reported to recognize it, 
and understand the selling intent and the economic model behind the practice. However, their understanding of the persuasive intent of influencer marketing was limited and even more importantly, when confronted with specific examples of sponsored content, they did not really know whether it was sponsored or not. Thus, their self-reported situational and dispositional conceptual advertising literacy did not align (Hudders et al., 2017). In addition, the dimensions of advertising literacy seem dissociated. The adolescents in our sample demonstrated comprehensive conceptual advertising literacy with regard to online influencer marketing but were lacking a general critical attitude (attitudinal advertising literacy) and reported to be accepting of the practice (positive moral advertising literacy). This positive moral knowledge is linked to adolescents' lack of critical attitudes due to a great perceived honesty of both the medium and the online influencers. In this study, the adolescents accepted the sponsorships as part of the influencer's content and took the perspective of the influencer as they understand the motivations of the influencer to engage in sponsorship deals. These findings are in line with previous research among adolescents, that also showed well-developed elements of conceptual advertising literacy, but lower levels of attitudinal advertising literacy regarding embedded advertising in television programs (Van Reijmersdal, 2017).

The second conclusion concerns adolescents' remarkable perspective on transparency. The perceived balance of the editorial and commercial content is very important. This balance is disrupted when the commercial messages overshadow the entertainment. Overshadowing could happen in cases in which a disclosure is presented by the influencer itself or by a third party. While the participants reported awareness of the sponsored content, they preferred to be ignorant, so they could still enjoy the content. This indicates that they are less aware of the sponsored messages than they report themselves because the entertainment would not be spoiled by a disclosure if they had already understood that the entertainment was actually advertising.

Moreover, this finding confirmed the concerns of policymakers, educational experts, and parents of adolescents' vulnerability within this context. As the adolescents seem to be very receptive to online influencer content while trying to ignore its commercial intentions at the same time, their situational advertising literacy seems low (Friestad \& Wright, 1994, Hudders et al., 2017), and therefore, their susceptibility to the integrated persuasive messages may be high. Adolescents may benefit from a disclosure to empower them as our findings showed that a disclosure elicited sponsorship recognition and a critical evaluation of the content, which seemed to be absent without a disclosure.

Third, adolescents seem to show reactance and change of meaning in response to disclosure that emphasize the commercial nature of the content (Brehm, 1966; Friestad \& Wright, 1994). In this situation, adolescents report avoidance and negative affect and also negative brand responses. In other words, when a disclosure informs adolescents about the actual intent of the sponsored video content, adolescents report a less favourable perspective of the content and its sender. These findings give insight into adolescents' perceptions of disclosures and into the role of disclosures in their evaluations of the content, sender and brand itself.

\section{Limitations and Future Research}

Despite conscientious preparation and design of the study, it has limitations. The present study provides valuable insights into adolescents' conceptual, moral, and attitudinal advertising literacy regarding sponsored influencer videos. However, advertising literacy encompasses more subdimensions (Friestad \& Wright, 1994; Boerman, Van Reijmersdal, Rozendaal, \& Dima, 2018), for example awareness of the effects of influencer marketing on oneself or another person. Future research could provide a more in-depth insight into adolescents' advertising literacy regarding influencer marketing, by taking more dimensions into account.

In addition, influencer marketing can take many forms, including sweep stakes, brand integration, simple brand placement. Future research is needed to get insights into the level of adolescents' conceptual, moral, and attitudinal advertising literacy regarding various formats. For example, some dimensions may be better developed for more prominent influencer marketing tactics than for more subtle ones.

In the present study, we examined advertising literacy and responses to disclosures for influencer marketing. Future research is needed to provide insights into the persuasive effects (e.g., buying behaviour, electronic word of mouth) of influencer marketing among adolescents. 
With respect to the method used, focus group discussions rely on group dynamics in which participants might come to their realisations only after hearing the thoughts of other discussion members. While we tried to account for this as much as possible by using individual tasks such as writing down thoughts and opinions, group dynamics might still have had some influence on the discussion that followed these tasks. Future studies may use one-onone interviews to avoid peer influence.

When interpreting the results, one should keep in mind that the present study is qualitative in nature. The aim is to provide insights into adolescents' perceptions and evaluations. To be able to draw more quantitative or generalizable conclusion, future research that uses other (quantitative) research methods is necessary.

\section{Theoretical and Practical Implications}

The findings of the current study have several theoretical and practical implications. Our findings are a starting point for further research concerning adolescents' advertising literacy of influencer marketing. Theoretically, it is important to note that this study showed a discrepancy between conceptual, moral and attitudinal advertising literacy. These findings imply that further specification of the advertising literacy model and of the various dimensions of advertising literacy is necessary to be able to understand and predict adolescents' perceptions of influencer marketing. In addition, so far, the moral dimension of advertising literacy has not received much attention yet (for an exception see Hudders et al., 2017; De Pauw et al., 2018). However, this concept seems to play an important role in the processing and acceptance of influencer marketing and therefore, deserves a role in advertising literacy theory.

In addition, existing advertising literacy measures could be improved by adding audiences' understanding and appreciation of the revenue model behind sponsored content as this showed to be an important element in adolescents' understanding of influencer marketing (see also Boerman et al., 2018). Adding this type of knowledge would offer further theoretical refinement to insights into adolescents' advertising literacy regarding influencer marketing.

Practically, marketers could persuade the influencer with which they are working to be honest about their collaboration. The discussions demonstrated that perceived honesty and transparency are characteristics of influencer videos that result in adolescents' acceptance of the practice. A disclosure could also be seen as an expression of honesty and therefore, be valued positively.

For regulators, the present study has interesting implications as well. Adolescents report that they prefer subtle disclosures that do not too explicitly state the persuasive intent of the sponsorship or that refer to advertising. However, these types of disclosures do seem valuable as they do enhance adolescents' conceptual advertising literacy and their critical attitudes toward influencer marketing. As disclosures are not created to be liked, but rather to inform receivers, our study implicates that explicit disclosures do seem advisable. In addition, regulations may suggest that influencers themselves disclose sponsored content as this would be appreciated by their adolescent audience. However, it would be advisable to work with adolescents to further develop both appreciated and effective forms of disclosures of influencer marketing, as has been done with younger children (De Jans, Vanwesenbeeck et al., 2018).

In conclusion, this study contributes to the literature in several ways. It is the first study to investigate adolescents' current state of advertising literacy regarding sponsored online influencer content and provides valuable insights for further studies on this topic. It demonstrates the contradiction of adolescents who prefer to be not too explicitly pointed to the persuasive nature of influencer marketing, while reporting to be fully aware of this aspect. This discrepancy highlights adolescents' vulnerability towards the hidden influencer marketing practices and shows the relevance of the current debate on adolescents' advertising literacy and the need for transparency. 


\section{References}

An, S., Jin, H. S., \& Park, E. H. (2014). Children's advertising literacy for advergames: Perception of the game as advertising. Journal of Advertising, 43, 63-72. https://doi.org/10.1080/00913367.2013.795123

Arnold, A. (2017, December 22). Four ways social media influences millenials' purchase decisions. Forbes. Retrieved from https://www.forbes.com/sites/andrewarnold/2017/12/22/4-ways-social-media-influencesmillennials-purchasing-decisions/\#7be25ff0539f

Boerman, S. C., Van Reijmersdal, E. A., Rozendaal, E., \& Dima, A. L. (2018). Development of the persuasion knowledge scales of sponsored content (PKS-SC). International Journal of Advertising, 37, 671-697.

https://doi.org/10.1080/02650487.2018.1470485

Braun, V., \& Clarke, V. (2013), Successful qualitative research: A practical guide for beginners. Thousand Oaks, CA: Sage.

Brehm, J. W. (1966). A theory of psychological reactance. Oxford, England: Academic Press.

Campbell, M. C., \& Kirmani, A. (2000). Consumers' use of persuasion knowledge: The effects of accessibility and cognitive capacity on perceptions of an influence agent. Journal of Consumer Research, 27, 69-83.

https://doi.org/10.1086/314309

Campbell, M. C., Mohr, G. S., \& Verlegh, P. W. J. (2013). Can disclosures lead consumers to resist covert persuasion? The important roles of disclosure timing and type of response. Journal of Consumer Psychology, 23, 483-495. https://doi.org/10.1016/j.jcps.2012.10.012

CAP. (2017). Online affiliate marketing. Retrieved from https://www.asa.org.uk/advice-online/affiliatemarketing.html

Charmaz, K. (2006). Constructing grounded theory: A practical guide through qualitative research. London, UK: Sage Publications Ltd.

De Jans, S., Cauberghe, V., \& Hudders, L. (2018). How an advertising disclosure alerts young adolescents to sponsored vlogs: The moderating role of a peer-based advertising literacy intervention through an informational vlog. Journal of Advertising, 47, 309-325. https://doi.org/10.1080/00913367.2018.1539363

De Jans, S., Vanwesenbeeck, I., Cauberghe, V., Hudders, L., Rozendaal, E., \& Van Reijmersdal, E. A. (2018). The development and testing of a child-inspired advertising disclosure to alert children to digital and embedded advertising. Journal of Advertising, 47, 255-259. https://doi.org/10.1080/00913367.2018.1463580

De Pauw, P., De Wolf, R., Hudders, L., \& Cauberghe, V. (2018). From persuasive messages to tactics: Exploring children's knowledge and judgement of new advertising formats. New Media \& Society, 20, 2604-2628.

https://doi.org/10.1177/1461444817728425

De Veirman, M., Cauberghe, V., \& Hudders, L. (2017). Marketing through Instagram influencers: The impact of number of followers and product divergence on brand attitude. International Journal of Advertising, 36, 798-828. https://doi.org/10.1080/02650487.2017.1348035

Defoe, I. N., Dubas, J. S., Figner, B., \& Van Aken, M. A. G. (2015). A meta-analysis on age differences in risky decision making: Adolescents versus children and adults. Psychological Bulletin, 141, 48-84.

https://doi.org/10.1037/a0038088

DefyMedia. (2016). Acumen report: Youth video diet. Retrieved from http://defymedia.com/acumen/acumenreport-youth-video-diet/ 
Dekker, K., \& Van Reijmersdal, E. A. (2013). Brand placement disclosures to mitigate persuasion: The role of celebrity endorsement and disclosure type. Journal of Promotion Management, 19, 224-240.

https://doi.org/10.1080/10496491.2013.769473

Evans, N. J., \& Park, D. (2015). Rethinking the persuasion knowledge model: Schematic antecedents and associative outcomes of persuasion knowledge activation for covert advertising. Journal of Current Issues \& Research in Advertising, 36, 157-176. https://doi.org/10.1080/10641734.2015.1023873

Evans, N. J., Phua, J., Lim, J., \& Jun, H. (2017). Disclosing Instagram influencer advertising: The effects of disclosure language on advertising recognition, attitudes, and behavioral intent. Journal of Interactive Advertising, 17, 138149.

Federal Trade Commission. (2009). 16 CFR part 255: Guides concerning the use of endorsements and testimonials in advertising. Retrieved from https://www.ftc.gov/sites/default/files/attachments/pressreleases/ftc-publishes-final-guides-governing-endorsements-testimonials/091005revisedendorsementguides.pdf

Flick, U. (2014). An introduction to qualitative research (5th ed.). London, UK: Sage.

Friestad, M., \& Wright, P. (1994). The persuasion knowledge model: How people cope with persuasion attempts. Journal of Consumer Research, 21, 1-31. https://doi.org/10.1086/209380

Ham, C.-D., Nelson, M. R., \& Das, S. (2015). How to measure persuasion knowledge. International Journal of Advertising, 34, 17-53. https://doi.org/10.1080/02650487.2014.994730

Hudders, L., De Pauw, P., Cauberghe, V., Panic, K., Zarouali, B., \& Rozendaal, E. (2017). Shedding new light on how advertising literacy can affect children's processing of embedded advertising formats: A future research agenda. Journal of Advertising, 46, 333-349. https://doi.org/10.1080/00913367.2016.1269303

Hwang, K., \& Zhang, Q. (2018). Influence of parasocial relationship between digital celebrities and their followers on followers' purchase and electronic word-of-mouth intentions, and persuasion knowledge. Computers in Human Behavior, 87, 155-173. https://doi.org/10.1016/j.chb.2018.05.029

ICAS. (2018, November 26). Standards foster transparency of influencer marketing. Retrieved from https://icas.global/standards-foster-transparency-of-influencer-marketing/

Lawlor, M. A., Dunne, Á., \& Rowley, J. (2016). Young consumers' brand communications literacy in a social networking site context. European Journal of Marketing, 50, 2018-2040. https://doi.org/10.1108/EJM-06-2015-0395

Livingstone, S., \& Helsper, E. J. (2006). Does advertising literacy mediate the effects of advertising on children? A critical examination of two linked research literatures in relation to obesity and food choice. Journal of Communication, 56, 560-584. https://doi.org/10.1111/j.1460-2466.2006.00301.x

Moore, E. S., \& Rideout, V. J. (2007). The online marketing of food to children: Is it just fun and games? Journal of Public Policy \& Marketing, 26, 202-220. https://doi.org/10.1509/jppm.26.2.202

Rozendaal, E., Lapierre, M. A., Van Reijmersdal, E. A., \& Buijzen, M. (2011). Reconsidering advertising literacy as a defense against advertising effects. Media Psychology, 14, 333-354.

https://doi.org/10.1080/15213269.2011.620540

Rozendaal, E., Opree, S. J., \& Buijzen, M. (2016). Development and validation of a survey instrument to measure children's advertising literacy. Media Psychology, 19, 72-100. https://doi.org/10.1080/15213269.2014.885843

Rozendaal, E., Slot, N., Van Reijmersdal, E. A., \& Buijzen, M. (2013). Children's responses to advertising in social games. Journal of Advertising, 42, 142-154. https://doi.org/10.1080/00913367.2013.774588 
Valkenburg, P. M., \& Piotrowski, J. T. (2017). Plugged in: How media attract and affect youth. New Haven, CT/London, UK: Yale University Press.

Van Noort, G., Antheunis, M. L., \& Van Reijmersdal, E. A. (2012). Social connections and the persuasiveness of viral campaigns in social network sites: Persuasive intent as the underlying mechanism. Journal of Marketing Communications, 18, 39-53. https://doi.org/10.1080/13527266.2011.620764

Van Reijmersdal, E. A., Boerman, S. C., Buijzen, M., \& Rozendaal, E. (2017). This is advertising! Effects of disclosing television brand placement on adolescents. Journal of Youth and Adolescence, 46(2), 328-342.

https://doi.org/10.1007/s10964-016-0493-3

Van Reijmersdal, E. A., Lammers, N., Rozendaal, E., \& Buijzen, M. (2015). Disclosing the persuasive nature of advergames: Moderation effects of mood on brand responses via persuasion knowledge. International Journal of Advertising, 34, 70-84. https://doi.org/10.1080/02650487.2014.993795

Van Reijmersdal, E. A., Tutaj, K., \& Boerman, S. C. (2013). The effects of brand placement disclosures on skepticism and brand memory. Communications - The European Journal of Communication Research, 38, 127-146. https://doi.org/10.1515/commun-2013-0008

Vanwesenbeeck, I., Ponnet, K., \& Walrave, M. (2017). Young adolescents' advertising literacy and purchase intention in social network games: Influence of perspective taking and need for cognition. Journal of Consumer Behaviour, 16, 23-33. https://doi.org/10.1002/cb.1596

Vanwesenbeeck, I., Walrave, M., \& Ponnet, K. (2016). Young adolescents and advertising on social network games: A structural equation model of perceived parental media mediation, advertising literacy, and behavioral intention. Journal of Advertising, 45, 183-197. https://doi.org/10.1080/00913367.2015.1123125

Verhellen, Y., Oates, C., De Pelsmacker, P., \& Dens, N. (2014). Children's responses to traditional versus hybrid advertising formats: The moderating role of persuasion knowledge. Journal of Consumer Policy, 37, 235-255. https://doi.org/10.1007/s10603-014-9257-1

Wojdynski, B. W., \& Evans, N. J. (2016). Going native: Effects of disclosure position and language on the recognition and evaluation of online native advertising. Journal of Advertising, 45, 157-168.

https://doi.org/10.1080/00913367.2015.1115380

Zarouali, B., Poels, K., Ponnet, K., \& Walrave, M. (2018). “Everything under control?": Privacy control salience influences both critical processing and perceived persuasiveness of targeted advertising among adolescents. Cyberpsychology: Journal of Psychosocial Research on Cyberspace, 12(1), article 5. https://doi.org/10.5817/CP2018-15

Zarouali, B., Poels, K., Walrave, M., \& Ponnet, K. (2018). 'You talking to me?' The influence of peer communication on adolescents' persuasion knowledge and attitude towards social advertisements. Behaviour \& Information Technology, 37, 502-516. https://doi.org/10.1080/0144929X.2018.1458903

Zarouali, B., Ponnet, K., Walrave, M., \& Poels, K. (2017). "Do you like cookies?" Adolescents' skeptical processing of retargeted Facebook-ads and the moderating role of privacy concern and a textual debriefing. Computers in Human Behavior, 69, 157-165. https://doi.org/10.1016/j.chb.2016.11.050 


\section{Appendix}

\section{Focus Group Discussion Guide}

Part 1: Start of discussion. Welcome everyone and it's really nice that you want to take part in this group discussion. We will talk about videos on YouTube. Please, take something to drink and/or to snack when you feel like it.

Rules.

- We're aiming to have a group conversation

- You can always respond to the other person, but let everyone finish

- $\quad$ Teachers, fellow students or your parents will not be told what you have said here

- It's about your opinion, this means that there are no wrong answers

- $\quad$ The letter will explain all these things again, which you can sign if you give approval for your participation

\section{Part 2: Familiarity YouTube.}

Introduction topic

- Who does ever watch vlogs on YouTube?

- Could you explain what vlogs are?

- Can anyone add to this?

- What is your opinion on vlogs?

○ Why?

Conceptual advertising literacy

- Do you ever encounter brands in vlogs?

- In what way do they appear?

\section{Part 3: Sponsored video.}

Focus on native advertising in vlogs $\rightarrow$ conceptual and attitudinal PK

- $\quad$ Showing sponsored video

○ What happens in this video?

> Task: write down everything that you notice / thoughts

$>$ Making word cloud of notes

- Notes about brands/products:

- What did you notice?

- Do you see this regularly?

- Why do you think they do this?

- Notes about advertising:

- How does this work? (what kind of advertising with YouTubers are there) 
- What do you think about this? (honest/fun/good/stupid)

Why?

Effectivity

- Do you think this way of advertising works?

- Why do you think this?

- $\quad$ And if you compare this to (traditional) TV advertising

- Why is there a / no difference?

Vlogger

- What do you think of the vlogger?

- Why do you think this?

- What do you think of the fact that the vlogger says something about this brand?

- Is this vlogger an expert?

- Do you believe what the vlogger says?

- Is it nice that this vlogger says something about the product?

\section{Part 4: Disclosures.}

\section{Explanation sponsorships}

Nowadays there has been many advertising on social media and consequently also on YouTube. This often is in collaboration with YouTubers. There are several ways how this can occur:

1. A sponsorship whereby the YouTuber get paid to talk about a certain product in his/her video.

2. The brand sends the YouTuber free products, hoping that the product will appear in a video of the YouTuber, either casually or for example in form of a product review.

3. A collaboration between the brand and the YouTuber, wherein the YouTuber a discount code can give to his/her audience. Every time a product is bought via the YouTuber, he/she will get a small part of the returns.

- Does this sound familiar to anyone?

- Can you elaborate on your experience?

- What do you think about this?

\section{Disclosures}

- Sometimes the vlogger says something themselves about the collaboration with the brand. But often it's not clear whether there's advertising in the video.

- What do you think about this? 
- Does this need to be clear or is it good the way it is?

- Why?

- What are ways we could think of to make it clear to the audience of vlogs that it contains advertising?

$>$ Task: write down several ways how we can make this clear

$>$ Making word cloud of our ideas

$>$ What is the conclusion? Different disclosures? Self-disclosure by the vlogger? YouTube as platform has to disclose? Prohibit this way of advertising?

- Showing two disclosures

- [YouTube influencer] is paid by Doritos to advertise in this video

- What do you think of this text?

- How would you respond if this text is added to the video you just saw?

- How does it make you feel?

- [YouTube influencer] is paid by Doritos to advertise in this video, so you will like Doritos

- What do you think of this text?

- How would you respond if this text is added to the video you just saw?

- How does it make you feel?

- Which one do you prefer?

- Why?

- Would you listen to what's written in this disclosure?

\section{Conclusion}

That was everything I wanted to know. We are now finished with our group discussion!

- $\quad$ Are there any questions?

- If you think of anything you want to know afterwards, you can always contact the researcher.

- Thank you again for your help. 


\section{Correspondence to:}

Eva van Reijmersdal

ASCOR

University of Amsterdam

Nieuwe Achtergracht 166

1018 WV Amsterdam

The Netherlands

Email: E.A.vanReijmersdal(at)uva.nl

Editorial record: First submission received on October 18, 2018. Revisions received on January 28, 2019, April 1, 2019, and May 14, 2019. Accepted for publication on May 15, 2019.

The article is part of the Special Issue "Digital Advertising and Consumer Empowerment" guest edited by Liselot Hudders (Ghent University, Ghent, Belgium), Karolien Poels (University of Antwerp, Antwerp, Belgium), and Eva van Reijmersdal (University of Amsterdam, Amsterdam, The Netherlands).

\section{About Authors}

Sophia van Dam obtained her Research Master degree in Communication Science at the University of Amsterdam. Her research interests include young consumers, their advertising literacy and online persuasive strategies targeting this group. Today she focuses on youth connecting with nature and sustainability as a communication specialist at a foundation dedicated to nature education.

Eva van Reijmersdal is an associate professor of Persuasive Communication at the Amsterdam School of Communication Research, ASCoR, University of Amsterdam, The Netherlands. Her research focuses on the effects of various forms of embedded advertising, including advergames, influencer marketing, and brand placements. Recently, she received an ASPASIA grant from the Dutch Science Foundation (NWO) for a five-year research project on the impact of disclosing the persuasive nature of embedded advertising on persuasion knowledge and persuasion among adults and children. She has published in a wide range of SSCl-ranked journals, including Journal of Youth and Adolescents, Computers in Human Behavior, Journal of Interactive Marketing, International Journal of Advertising and American Behavioral Scientist. Van Reijmersdal is an Associate Editor of the International Journal of Advertising and former board member of NeFCA's Persuasive Communication Division. 